\title{
System Stability Analysis in Two Area System Integration with Three Renewable Energy Resources
}

\author{
Pramod Kumar Meher \\ M. Tech. Scholar \\ NRI Institute of Research \& Technology \\ Bhopal, India \\ meherpramodkumar007@gmail.com
}

\author{
Mrs. Madhu Upadhyay \\ Head of Department \\ NRI Institute of Research \& Technology \\ Bhopal, India \\ madyant44@gmail.com
}

\begin{abstract}
Stability is the most important feature required in the modern electrical system. In recent years, grid stability problems have been detected due to the rapid growth of electrical and electronic loads. To study the system performance under the effect renewable energy based generating units the kundur's two area system has been taken as test system. The direct integration of these resources were studied for various instability issues like rotor angle stability, power stability at the generating points of machines and distortion level in the voltage and current waveforms of the grid system. The work has proposed a universal dynamic system optimizing control for system stability enhancement in all the aspects. The MATLAB/SIMULINK environment being the platform for the system designing and implementation, The effects on the two area four machines system has been studied by integrating wind energy system without dynamics optimization control in area 1and then systems with both solar and wind with the dynamic optimization controller at area 2 was developed. The study is further carried to integration of a fuel cell system in area 1 as well. The rotor angle stability and power stability at the point of generation bus was also stabilized by the proposed control in the power system.
\end{abstract}

Keywords: DFIG, STATCOM, THD, PSS.

\section{INTRODUCTION}

Stability is the most important feature required in the modern electrical system. In recent years, grid stability problems have been detected due to the rapid growth of electrical and electronic loads. However, developments and improvements in generation and distribution systems have yet to respond to these rapidly growing loads and the growing number of large and sensitive devices in the power grid. Failures and brief interruptions of generators or transmission lines always have a negative effect on the power grid.

Furthermore, a rapid variety of loads in the system cause voltage and frequency fluctuations. These disturbances and fluctuations that occur during the transition process lead to stability and quality problems in the power grid [1]. The stability of the power system is subject to changes in the system or in the charge level, which can be sudden or gradual and be subject to major or minor changes. Stability is an important concept that determines the stable operation of the electrical system.

Rotor angular stability is commonly used as an index, but the concept of transient stability, which is a function of operating conditions and disturbances, refers to the ability of the system to remain intact after being subjected to abnormal deviations. A system is said to be synchronously stable for a given error if the system variables adapt to certain steady-state values in the time after the error has been eliminated [2]. The grid stability analysis has been recognized as an important and difficult problem for the safe operation of the system. If major disturbances occur in interconnected electrical networks, the safety of these electrical networks must be checked.

\section{LITERATURE REVIEW}

Mohammad javad Morshed et al. [1] This paper proposes a novel non-linear control approach to coordinate dualpower induction generator (DFIG) wind turbines and synchronous static compensator controllers in multimachine power systems. The main goal is to improve the transient and voltage stability of the interconnected multi- 
machine power system by simultaneously designing the DFIG rotor voltage and the STATCOM reference current.

E. Sharifi et al. [2] This research will focus on the transient stability of multi-machine propulsion systems, taking full account of the performance of the TakagiSugeno fuzzy-based slip mode control approach in combination with the traditional slip mode. only on the optimal control approaches to improve the bottom line in this area. In fact, with regard to the robustness of the sliding mode control approach to parametric uncertainties and environmental disturbances, several different sliding mode control approaches are designed for comparison according to a series of prior art considerations.

Mahmoud Reza Shakarami et al. [3] This paper proposes a method for designing a Large Area Power System Stabilizer based on the Gray Wolf Optimization Algorithm. The stabilizer is used to dampen oscillations between zones by taking into account the communication latency associated with remote return signals. For this reason, a new multi-objective function is proposed for WAPSS design. In this feature, the stabilizer is designed with lower control gain as well as improving system stability by shifting critical modes to the minimum stage.

Ram Krishan et al. [4] Oscillatory instability in modern electrical systems has increased due to the increasing complexity and integration of dynamic loads. The stability analysis of such an interconnected network is very important when the load/production is uncertain. This paper presents a power system stabilizer design approach that aims to improve the oscillatory stability of the multi-machine power system in the specified uncertainty range in the expected load / production.

\section{OBJeCTIVE}

The work is intended to achieve the following key objectives while designing and simulation:

- Designing of a two area four machines system in MATLAB/SIMULINK environment which has to be integrated with wind energy system for deriving the test system under analysis. The renewable energy resource is modeled with variation in input wind speed parameters.

- Analyzing the system dynamics performance and effects of integrating a variable generating resource on the grid.
- The further solar and fuel cell systems has to be integrated and effects on the stability of grid has to be analyzed. Designing of an efficient dynamics controller with an efficient intelligent controller for the same

- The two area system is studied for variations in rotor angle of machines, THD levels in output parameters and power stability at the machine generating points. The aim is to develop a two area kundur's system coherently integrated with the solar/wind/FC systems with disturbances suppressed by the designed controller

$$
\text { IV. Methodology }
$$

\section{A. Modeling Two Area System}

Rotor angular stability refers to the ability to maintain / restore synchronicity after a failure has occurred in an interconnected electrical system. In normal system operation, all synchronous machines rotate at the same electrical speed $2 \pi f$. The mechanical and electromagnetic couples acting on the rotating masses of each generator are balanced and the phase angle differences between the internal electromagnetic fields of the various machines are constant and remain synchronous. After a failure, a change in rotor speed is caused by a torque imbalance, resulting in a loss of synchronism.

To analyze grid stability with two 4-machine surface systems, we integrated different renewable energy sources and examined the effects of integration on them. The Kundur two-surface system is initially used as a test model, which undergoes a) wind energy integration b) solar / wind hybrid system integration and c) solar / wind /fuel battery integration. The test system is completely modified with three renewable energies for the production of electricity. Stability is examined on the machine and spawn points after integration.

The impact was apparently high in terms of acceptable limits, and from now on the design of a dynamic system optimization controller was developed, using anticipatory neural learning of system dynamics to achieve stable system behavior in all aspects.

\section{B. Development of test system}

In general, a bus in an electrical power system is fed from the generating units which inject the active and reactive power into it and loads real and reactive power $\mathrm{s}$ from it. In load flow studies, the generator and load (complex) powers are lumped into a net power. This net power is 
called bus injected power. The net power injected in the bus is given by:

$\mathrm{S}=\mathrm{P}+\mathrm{jQ}=\mathrm{P}_{\mathrm{G}}+\mathrm{JQ}_{\mathrm{G}}-\mathrm{P}_{\mathrm{D}}+\mathrm{JQ}_{\mathrm{D}}$

The test system chosen comprises of two areas with four machines. The system is integrated with the highly variable feeding wind energy resource. The single line diagram of the sytem has been depicted in figure.

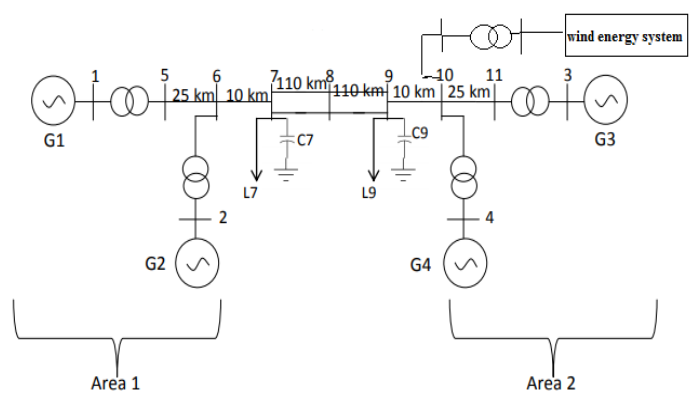

Fig. 1 Single line diagram of two area system on wind integration

Each step-up transformer has an impedance of $0+\mathrm{j} 0.15$ per unit on 900 MVA and $20 / 230 \mathrm{kV}$, and has an off-nominal ratio of 1.0. The transmission system nominal voltage is $230 \mathrm{kV}$. The line lengths are identified in Fig.1. The parameters of the line in per unit on $100 \mathrm{MVA}, 230 \mathrm{kV}$ base are:

\begin{tabular}{|l|l|}
\hline \multicolumn{2}{|l|}{ Table 1: Transmission line parameters in two area } \\
system \\
\hline $\mathrm{r}$ & $0.001 \mathrm{pu} / \mathrm{km}$ \\
\hline $\mathrm{x}_{\mathrm{L}}$ & $0.001 \mathrm{pu} / \mathrm{km}$ \\
\hline $\mathrm{b}_{\mathrm{c}}$ & $0.00175 \mathrm{pu} / \mathrm{km}$ \\
\hline
\end{tabular}

The system is meant to be operating with area 1 exporting $400 \mathrm{MW}$ to area 2. However integration with variable energy resource leads to certain variations at the loading points. The loads and reactive power supplied (QC) by the shunt capacitors at buses 7 and 9 are as follows:

\begin{tabular}{|l|l|l|l|}
\hline \multicolumn{4}{|l|}{ Table 2: Loading at the buses 9 and 7 } \\
\hline Bus & $\mathrm{P}_{\mathrm{L}}$ & $\mathrm{Q}_{\mathrm{L}}$ & $\mathrm{Q}_{\mathrm{C}}$ \\
\hline Bus 7 & $967 \mathrm{MW}$ & $100 \mathrm{MVAr}$ & $200 \mathrm{MVAr}$ \\
\hline Bus 9 & $1767 \mathrm{MW}$ & $100 \mathrm{MVAr}$ & $350 \mathrm{MVAr}$ \\
\hline
\end{tabular}

The following data and model has been taken from Kundur"s book. The system consists of a weak tie which connects two similar areas. Each area have two coupled units, each having a rating of $900 \mathrm{MVA}$ and $20 \mathrm{kV}$. The generator parameters in per unit on the rated MVA and $\mathrm{kV}$ are as follows:

\begin{tabular}{|l|l|}
\hline \multicolumn{2}{|l|}{ Table 3: Generator machine parameters in two area system } \\
\hline $\mathrm{X}_{\mathrm{d}}$ & 1.8 \\
\hline
\end{tabular}

\begin{tabular}{|l|l|}
\hline $\mathrm{X}_{\mathrm{q}}$ & 1.7 \\
\hline $\mathrm{X}_{\mathrm{t}}$ & 0.2 \\
\hline $\mathrm{X}_{\mathrm{d}}$ & 0.3 \\
\hline $\mathrm{X}_{\mathrm{q}}^{\prime}$ & 0.55 \\
\hline $\mathrm{X}_{\mathrm{d}}{ }_{\mathrm{d}}$ & 0.25 \\
\hline $\mathrm{X}_{\mathrm{q}}^{\prime \prime}$ & 0.25 \\
\hline $\mathrm{R}_{\mathrm{a}}$ & 0.0025 \\
\hline $\mathrm{T}_{\mathrm{d} 0}$ & $8.0 \mathrm{~s}$ \\
\hline $\mathrm{T}_{\mathrm{q} 0}$ & $0.4 \mathrm{~s}$ \\
\hline $\mathrm{T}_{\mathrm{d} 0}$ & $0.03 \mathrm{~s}$ \\
\hline $\mathrm{T}_{\mathrm{q} 0}^{\prime \prime}$ & $0.05 \mathrm{~s}$ \\
\hline
\end{tabular}

C. Wind/PV energy system integration with Kundur's two area machine model with variable wind speed and irradiation level:

Various modeling techniques are developed by researchers to model components of HRES. Performance of individual component is either modeled by deterministic or probabilistic approaches. This chapter discusses the basic modeling structures of solar energy system, and Wind energy system along with modeling of PSS controls.

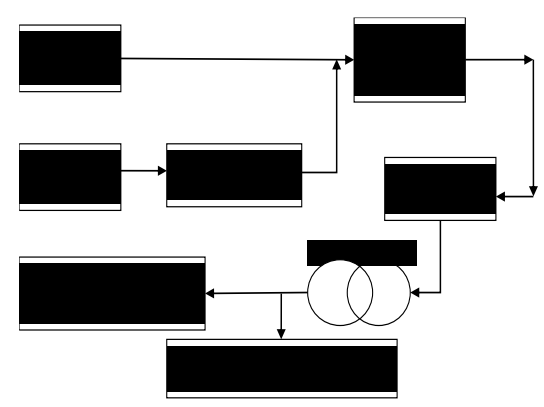

Fig. 2: Proposed Hybrid energy system topology

\section{PV Module modeling:}

Photovoltaic energy is available in abundance in the environment and without pollution. The type of output power of the photovoltaic system depends on the geographic location. The photovoltaic system is a potential renewable energy source with which it is possible to overcome the dependence on fossil fuels. The different combinations of hybrid PV/wind systems through battery storage and the DG supplementary unit are examined in order to investigate the potential benefits and efficient use of wind PV systems to meet consumer load requirements. The PV/wind based hybrid systems have complementary characteristics as follows

- Working cost of PV system is minimum as compared DG

- $\quad$ \& \& M cost minimum as compared DG diesel

- Reduces battery storage requirement 
- Better dependability

- Less emissions

- System autonomy

- Accuracy analysis

- Reduce generation costs and increase the reliability of energy supply

- Maximize the techno-economic benefits

- Find out a number of storage days

Grid-Connected PV system without a back-up energy storage (ES) are environmental friendly and frequently adopted by people due to less requirements for maintenance and cost. However, in the case of power outage during the night time or cloudy day, the system has to shut down the operation until the grid power is available. Grid-connected photovoltaic systems with a backup ES are usually grid-connected. This configuration offers several advantages, such as: For example, selling excess PV generation to the grid, charging the battery system during off-peak hours, and purchasing electricity from the grid to support loads when the PV is and the battery is insufficient. Renewable PV sources cannot provide constant energy supply and create a potential imbalance between production and demand, especially during off-peak periods when PV generates more energy and during peak periods when load demand increases. too much.

The power conditioning unit (PCU) or inverter is the main component of grid-connected photovoltaic / wind systems that convert the direct current generated by the photovoltaic generator into alternating current which meets the voltage and energy quality requirements from the power grid, use directly on the devices or send to the power supply to obtain tariff compensation. If the mains is not supplied, the PCU automatically cuts off the mains supply.

The photovoltaic cells have a single operating point in which the current (I) and voltage (V) values of the cell lead to the maximum output power. These values correspond to a particular resistance, which is equal to V/I. A simple equivalent circuit of PV cell is shown in Figure 3.4.

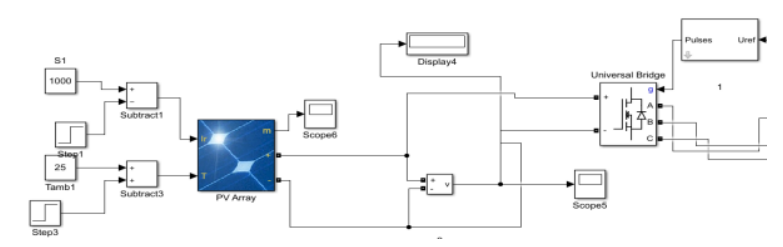

Fig. 3 Modeled solar system

A cell series resistance ( Rs ) is connected in series with parallel combination of cellphotocurrent ( $\mathrm{I}_{\mathrm{ph}}$ ),exponential diode (D), and shunt resistance $\left(\mathrm{R}_{\mathrm{sh}}\right)$, I pv and $\mathrm{Vpv}$ are the cells current and voltage respectively. It can be expressed as

$I_{p v}=I_{p h}-I_{S}\left(e^{q\left(V_{p v}+I_{p v} * R_{S}\right) / n K T}-1\right)-\left(V_{p v}+I_{p v} *\right.$ $\left.R_{S}\right) / R_{s h}$

$\mathrm{Eq}(1)$

Where:

$I p h^{-}$Solar-induced current

$I_{S}$ - Diode saturation current

$q$ - Electron charge $\left(1.6 \mathrm{e}^{-19} \mathrm{C}\right)$

$K$ - Boltzmann constant $\left(1.38 \mathrm{e}^{-23} \mathrm{~J} / \mathrm{K}\right)$

$n$ - Ideality factor (1 2)

$T$ - Temperature ${ }^{0} \mathrm{~K}$

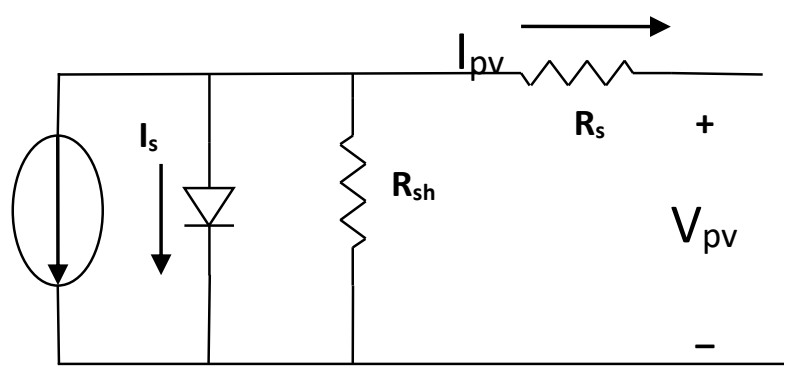

Fig. 4 Equivalent circuit of solar PV cell

The solar induced current of the solar PV cell depends on the solar irradiation level and the working temperature can be expressed as:

$I_{p h}=I_{s c}-k_{i}\left(T_{c}-T_{r}\right) * \frac{I_{r}}{1000} \quad \mathrm{Eq}(2)$

Where:

$I_{S C}$ Short-circuit current of cell at STC

$K_{i}$ Cellshort-circuit current/ temperature

coefficient $(\mathrm{A} / \mathrm{K})$

$I_{r}$ Irradiance in $\mathrm{w} / \mathrm{m} T_{C}, T_{r}$ Cell ${ }^{2}$ working and reference temperature at STC

A PV cell has an exponential relationship between current and voltage and the maximum power point (MPP) occur at the knee of the curve as shown in the Fig 5. 


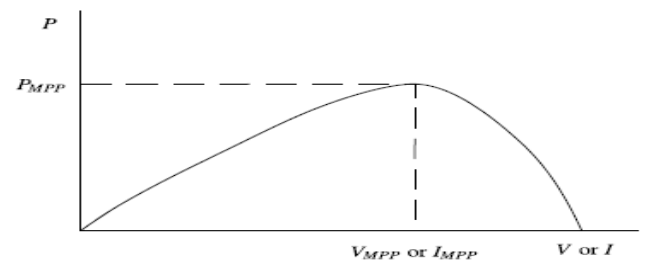

Fig. 5 Characteristic PV array power curve

\begin{tabular}{|l|l|}
\hline \multicolumn{2}{|l|}{ Table 4 : PV module Parameters } \\
\hline Model & 1 Soltech 1STH \\
\hline Maximum Power & 213.5 Watts \\
\hline Number of parallel strings & 40 \\
\hline Number series modules & 10 \\
\hline Open circuit voltage & 36.3 Volts \\
\hline Shot circuit current & 7.84 Ampere \\
\hline $\begin{array}{l}\text { Voltage at maximum power point } \\
\mathrm{V}_{\text {mp }}\end{array}$ & 29 Volts \\
\hline Irradiation & 500 to $1000 \mathrm{wb} / \mathrm{m}^{2}$ \\
\hline $\begin{array}{l}\text { Current at maximum power point } \\
\mathrm{I}_{\mathrm{mp}}\end{array}$ & 7.35 Ampere \\
\hline Temperature Coefficient of $\mathrm{V}_{\mathrm{oc}}$ & $-0.36099 \% / \mathrm{deg} . \mathrm{C}$ \\
\hline Temperature Coefficient of $\mathrm{I}_{\mathrm{sc}}$ & $0.102 \% /$ deg.C \\
\hline Temperature & $25^{\circ} \mathrm{C}$ \\
\hline
\end{tabular}

1. Rotor Hub and Blade

The interaction of the wind and the rotor blade is the most important factor in producing electricity. The rotor consists of large turbine blades and a hub. The blades look like the wings of an airplane. The blades are usually large. In practice, three-blade wind turbines are generally used. Another component of the rotor is the stepper drive, with which the speed of the rotor blades is maintained within the desired operating range between 1000 and $3600 \mathrm{rpm}$ (revolution per minute).

\section{Generator}

Wind energy spins two or three propeller blades around a rotor. The rotor is connected to the main shaft, which spins a generator to generate electricity. The generator thus converts the mechanical energy of the wind turbine rotor into electrical energy.

The model of a wind turbine with PMSG wind turbines cannot fully capture wind energy. The components of the wind turbine were modeled by the following equations.

Output aerodynamic power of the wind-turbine is expressed as:

$P_{\text {Turbine }}=\frac{1}{2} \rho A C_{p}(\lambda, \beta) v^{3}$

where, $\rho$ is the air density (typically $1.225 \mathrm{~kg} / \mathrm{m} 3$ ), $A$ is the area swept by the rotor blades (in $\mathrm{m} 2$ ), $C P$ is the coefficient of power conversion and $v$ is the wind speed (in $\mathrm{m} / \mathrm{s}$ ).

The tip-speed ratio is defined as:

$\lambda=\frac{\omega_{m} R}{v}$

where $\omega_{m}$ and $R$ are the rotor angular velocity (in $\mathrm{rad} / \mathrm{sec}$ ) and rotor radium (in $\mathrm{m}$ ), respectively.

The wind turbine mechanical torque output $m T$ given as:

$T_{m}=\frac{1}{2} \rho A C_{p}(\lambda, \beta) v^{3} \frac{1}{\omega_{m}}$

The power coefficient is a nonlinear function of the tipspeed ratio $\lambda$ and the blade pitch angle $\beta$ (in degrees). Then Power output is given by

$P_{\text {Turbine }}=\frac{1}{2} \rho A C_{p_{\text {max }}} v^{3}$

A generic equation is used to model the power coefficient $C_{P}$ based on the modeling turbinecharacteristics described in [2], [7-9] and [11] as:

$C_{p}=\frac{1}{2}\left(\frac{116}{\lambda_{i}}-0.4 \beta-5\right) e^{-\left(\frac{21}{\lambda_{i}}\right)}$

For each wind speed, there exists a specific point in the wind generator power characteristic, MPPT, where the output power is maximized. Thus, the control of the WECS load results in a variable-speed operation of the turbine rotor, so the maximum power is extracted continuously from the wind.
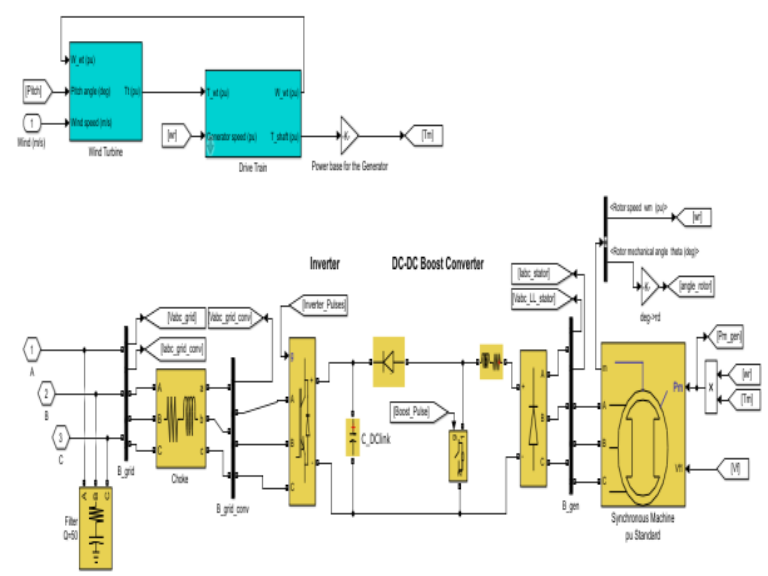

Fig. 6 modeled Wind system

This mechanism uses the variable torque output $\mathrm{w}_{\mathrm{m}}$ and tries to optimize the output current and voltage waveform to its maximum value.

\section{Solar/Wind/fuel cell system integration}


The PEMFC is an electrochemical device that converts the chemical energy contained in a reaction between a fuel, hydrogen and an oxidant, oxygen, into electrical energy. A bias voltage is applied to the electrochemical cell to induce electrochemical reactions on the two electrodes. Water is introduced to the anode and dissociated into oxygen, protons and electrons. Protons are driven by an electric field through the PEM to the cathode, where they combine with electrons arriving from the external circuit to form hydrogen gas.

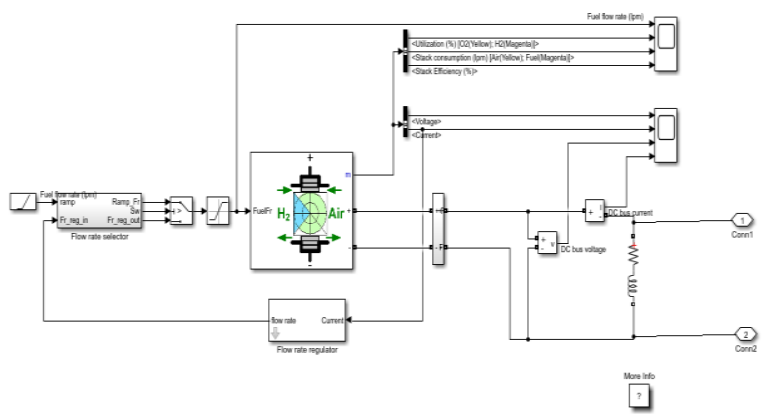

Fig. 7 MATLAB/SIMULINK model of fuel system

Fuel cells are compact, low-noise energy generators that use hydrogen and oxygen to generate electricity. The transport sector is the most important potential market for fuel cells and car manufacturers invest heavily in research and development. However, energy production is seen as a market in which fuel cells can be marketed much faster Fuel cells can achieve high efficiency $(35 \%-60 \%)$ compared to conventional technologies. The figure 3.7 shows the approach that has been followed to integrate the system with in area 1 of the kundur's two area system.

\section{J. $\quad$ Feed Forward Neural Learning}

This chapter shall discuss the various control techniques that are being implemented with the controller for its efficiency evaluation in terms of rotor angle stability and THD level evaluation as well as generation point stability on integration with the variable renewable energy resources. The various block diagrams associated with working of controller utilizing the neural baed learning of system dynamics is being discussed along with its control algorithms. The flow chart of the dynamic system optimization control is given.

K. Feed forward Neural network based learning of system dynamics arriving at the integration

ANNs are information processing systems that simulate the behavior of the human. ANNs obtain the inherent information from the considered features and learn from the input data, even when our model has noise. ANN structure is composed of essential information processing units, which are neurons.

They are defined into several layers and interconnected with each other by defining weights. Synaptic weights show the interaction between every pair of neurons. These structures distribute information through the neurons. The mappings of inputs and estimated output responses are calculated through combinations of different transfer functions. We can use the self-adaptive information model recognition methodology to analyze the learning algorithms of artificial neural networks.

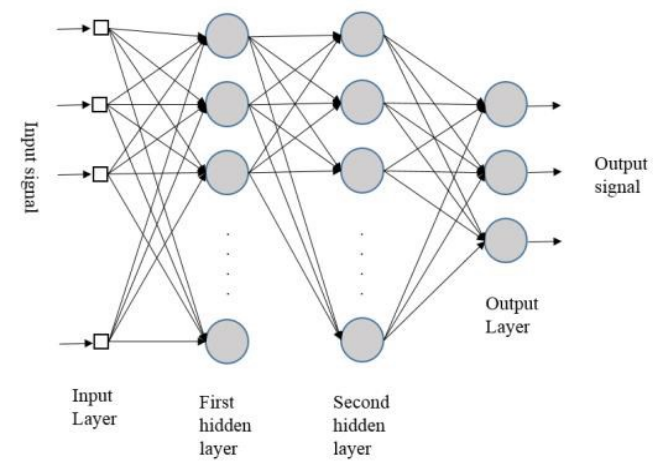

Fig. 8 Architectural Graph of an MLP Network with Two Hidden Layers.

Neural networks can be divided into single-layer perception and multilayer perception (MLP) networks. The multilayer perception network includes multiple layers of simple, two state, sigmoid transfer functions having processing neurons that interact by applying weighted connections. A typical feed-forward multilayer perception neural network consists of the input layer, the output layer, and the hidden layer. The multilayer perception (MLP) with the back propagation learning algorithm is used in this study because numerous previous researchers used this type of ANN, and it is also a general function approximation.

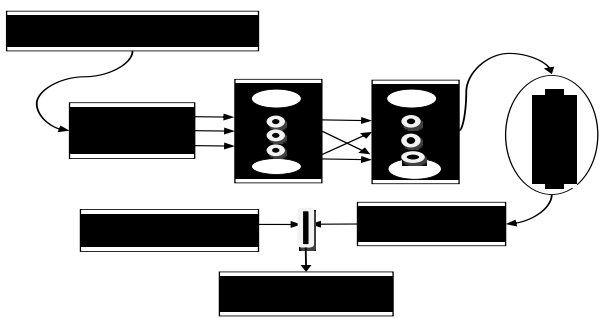

Fig. 9 PSO - NN controller Technique implemented in MATLAB/SIMULINK 
The development of ANN models was based on studying the relationship of input variables and output variables. Basically, the neural architecture consisted of three or more layers, i.e. input layer, output layer and hidden layer as shown in Fig. The function of this network was described as follows:

$Y_{j}=\mathrm{f}\left(\sum w_{i j} X_{i j}\right)$

whereYj is the output of node $\mathrm{j}, \mathrm{f}($.$) is the transfer$ function. wij the connection weight between node $\mathrm{j}$ and node $\mathrm{i}$ in the lower layer and $\mathrm{Xij}$ is the input signal from the node $i$ in the lower layer to node $j$. The development of the controller was attained with employing an IGBT based automatic switching of the bridge circuit with proper controlling optimizing algorithm for acquiring machine stability at the grid. The study of system oscillations is made inclusive with that of system electrical output parameters and a neural network is trained for optimum learning of the system through it. The variations arising with the integration of the renewable energy resources is being studied and mitigated by generating signals to A IGBT based bridge circuit that produces output so as to balance the disturbances. The flow chart of the system control utilized in the development of the proposed system dynamics controller has been depicted in fig. 9. The incremental addition of new hidden units allows for the hidden units to have variable activation functions. Although sigmoidal triggering functions are best suited for networks with binary outputs, this is not necessarily the case with continuously weighted outputs. Allowing new hidden units with different activation functions can lead to smoother approximations and faster learning with less computation and hidden units required.

\section{Results}

MATLAB stands for MATrix LABoratory, which is a programming package exclusively designed for speedy and effortless logical calculations and Input/output. It has factually hundreds of inbuilt functions for a large form of computations and plenty of toolboxes designed for specific analysis disciplines, as well as statistics, optimization, solution of partial differential equations, information analysis. In this research work MATLAB platform is used to show the implementation or simulation of implemented algorithm performance. Measurement toolboxes are used and some inbuilt functions for generating graphs are used. Simulation results and comparison of the performance of implemented model with some existing ones are calculated by MATLAB functions.

The world is moving from its current centralized generation to a future with a greater proportion of the distributed generation. Hybrid energy systems are linked with wind power, photovoltaic and fuel cells to generate electricity for local load and to connect it to grids / microgrids that reduce dependence on fossil fuels. The hybrid system is a better option for building modern power grids that provide economic, environmental and social benefits. The work has focused on stabilizing grid parameters on integration of these energy resources at various points. For this the two area test system has been deployed and the analysis is done on the following mentioned cases.

Case 1: Two area system with wind integration with STATCOM without any controller

Case 2: Two area system with wind-solar integration and dynamic system optimizing control for system stability enhancement

Case 3: Two area system with wind-solar and Fuel cell integration and dynamic system optimizing control for system stability enhancement

Discussed the variations in the total harmonic distortion in the voltage and current waveforms, rotor angle deviations, power stability in p.u at generating points and rotor speed variations to study the effectiveness of the designed dynamic system optimization controller.

Case 1: Two area system with wind integration with STATCOM without any controller

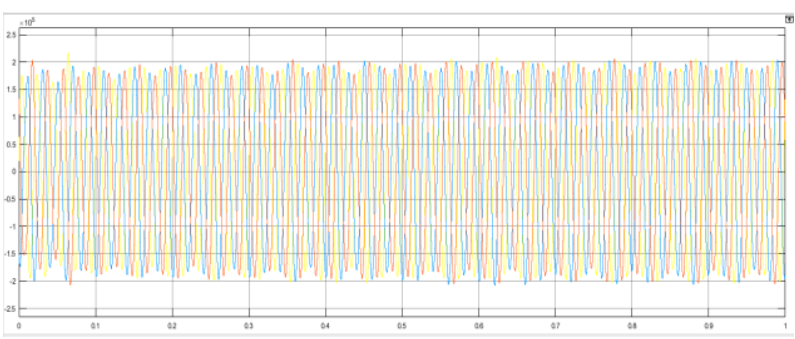

Fig. 10 Voltage at the grid

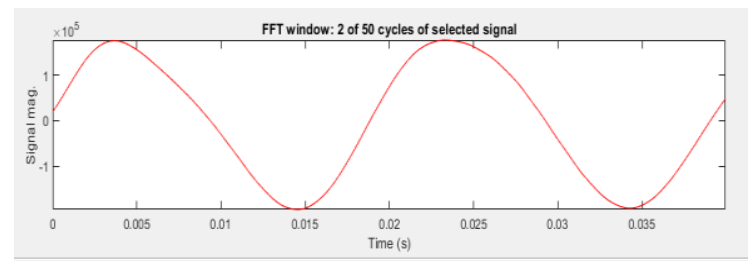


Fig. 11 FFT analysis of voltage at the grid

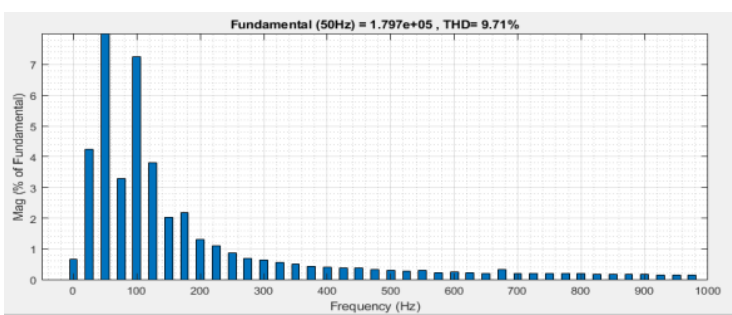

Fig. 12 THD \% in voltage at the grid

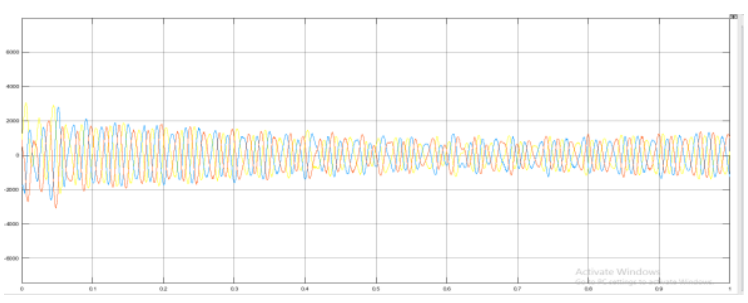

Fig. 13 Current at the grid

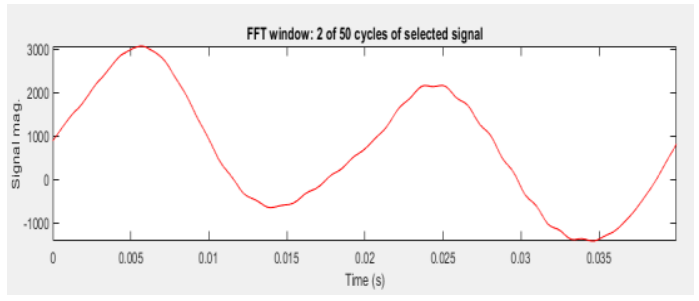

Fig. 14 FFT analysis of current at the grid

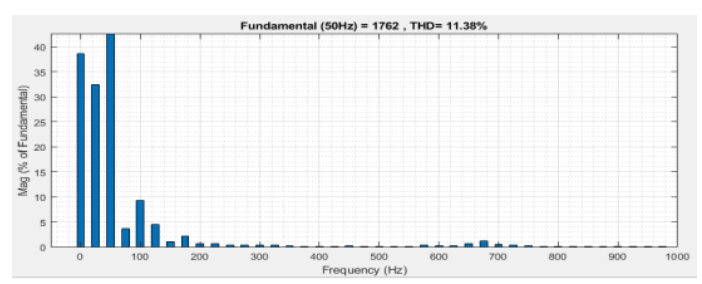

Figure $5.6 \mathrm{THD} \%$ in current at the grid

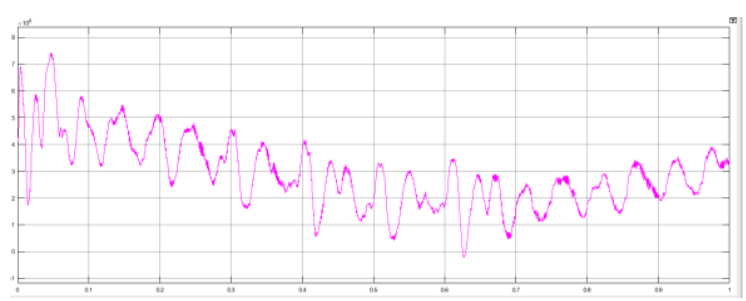

Fig. 15 Active power at the grid

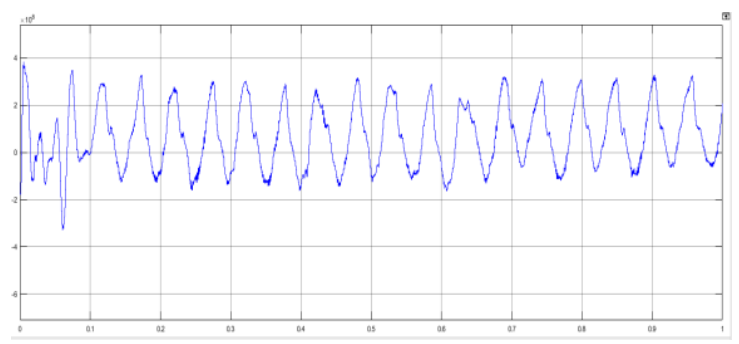

Fig. 16 Reactive power at the grid

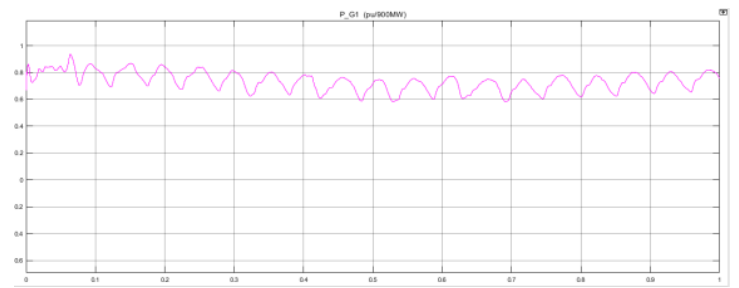

Fig. 17 Power stability in p.u at the generating terminal of machines

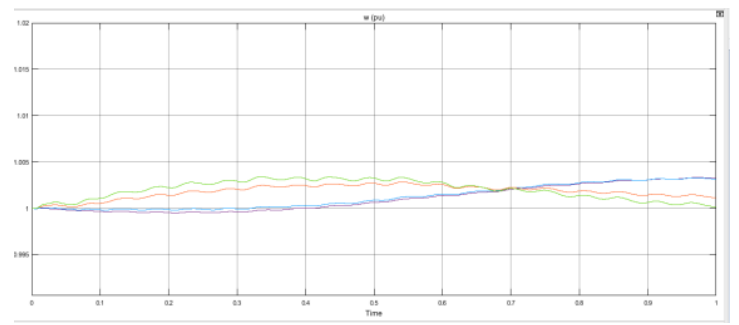

Fig. 18 Rotor Speed variations on wind integration

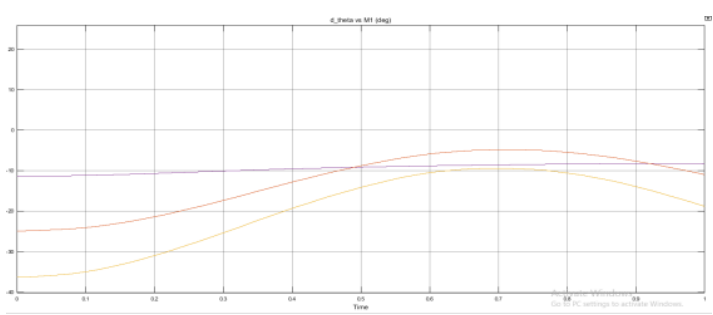

Fig. 19 Rotor Angle Deviation at the machines on integration with wind energy resource

Case 2: Two area system with wind-solar integration and dynamic system optimizing control for system stability enhancement.

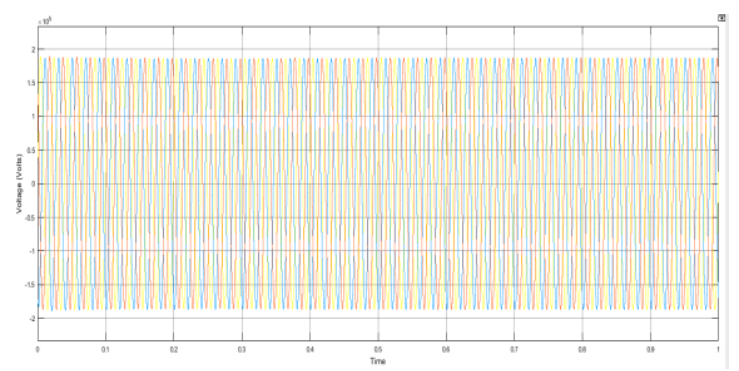

Fig. 20 Voltage at the grid in two area wind-PV integrated system with Dynamic system optimization control 


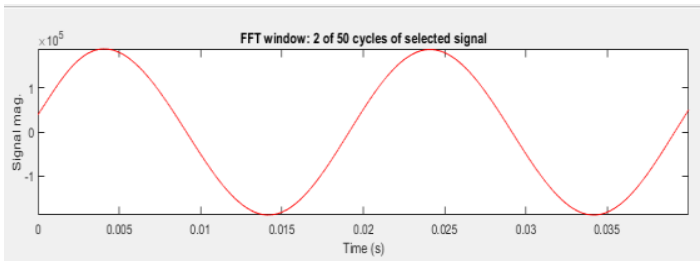

Fig. 21 FFT Analysis of voltage at the grid

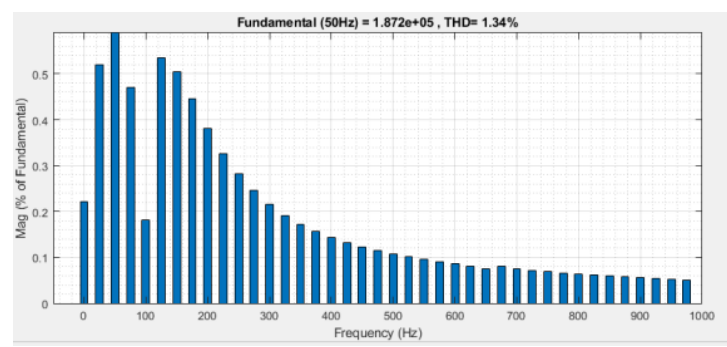

Fig. 22 THD\% in voltage at the grid

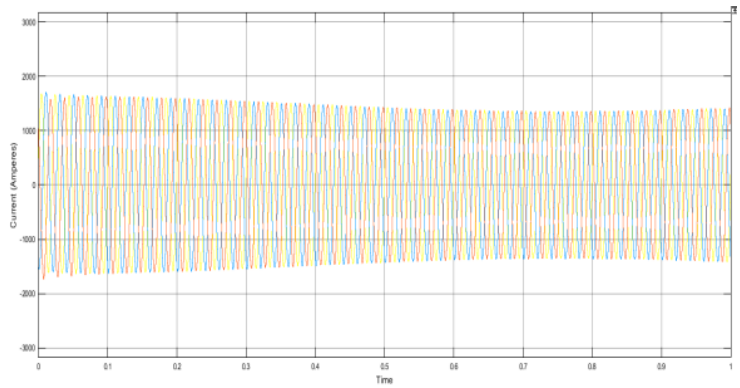

Fig. 23 Current at the grid in two area wind-PV integrated system with Dynamic system optimization control

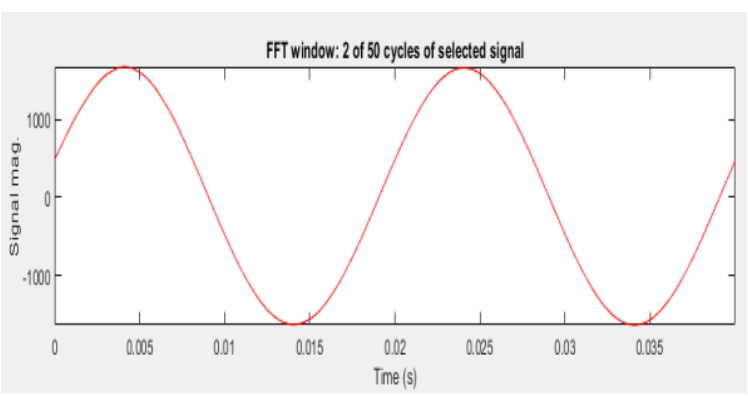

Fig. 24 FFT Analysis of current at the grid

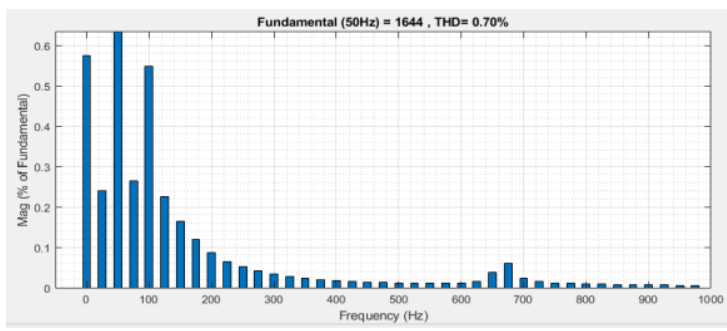

Fig. $25 \mathrm{THD} \%$ in current at the grid

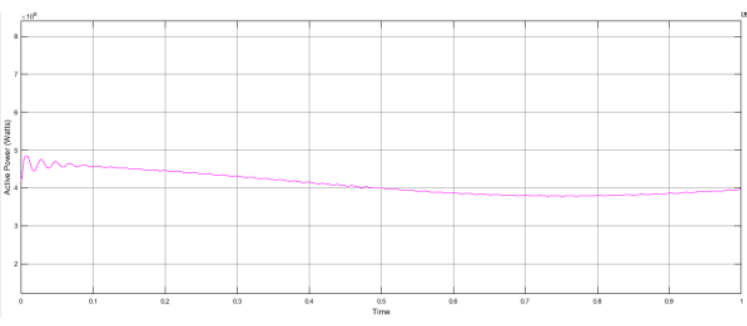

Fig. 26 Active Power at the grid in two area wind-PV integrated system with Dynamic system optimization control

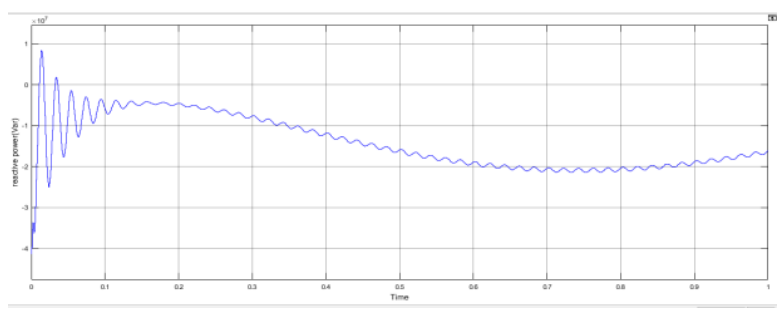

Fig. 27 Reactive Power at the grid in two area wind-PV integrated system with Dynamic system optimization control

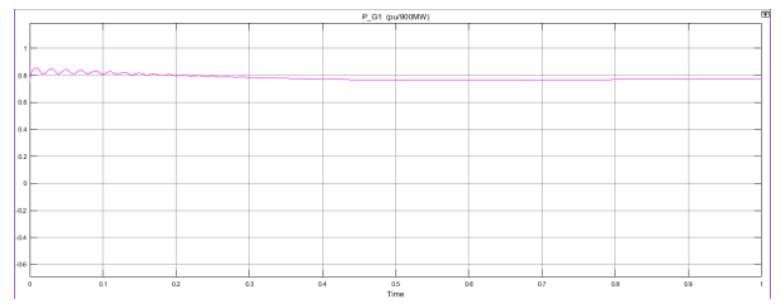

Fig. 28 Power stability in p.u at the generating terminal of machines

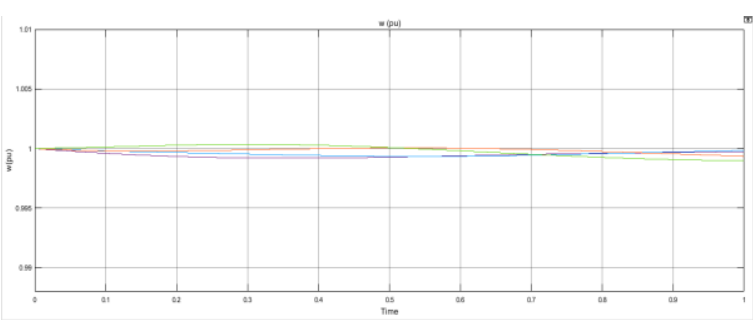

Fig. 29 Rotor Speed variations on wind/Solar integration with Dynamic system optimization control

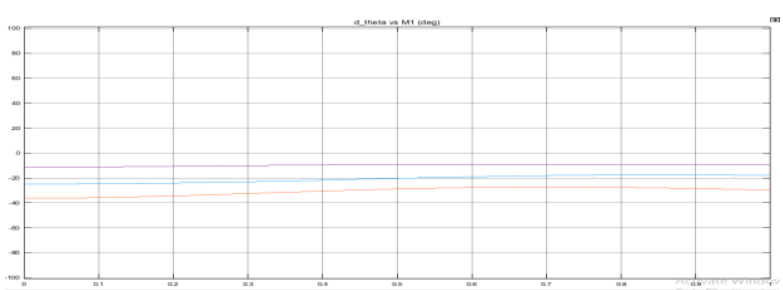

Fig. 30 Rotor angle deviation in machines with wind/solar integration and controller

Case 3: Two area system with wind-solar and Fuel cell integration and dynamic system optimizing control for system stability enhancement. 


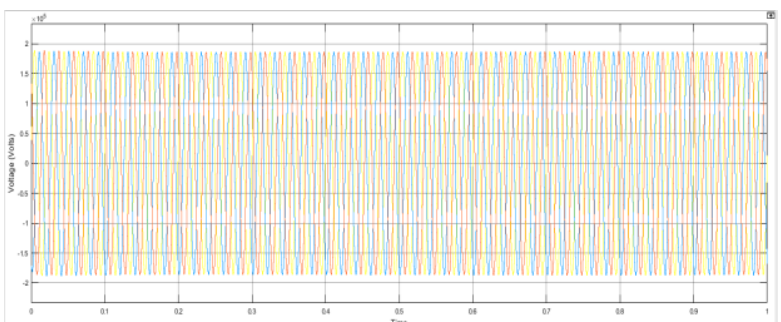

Fig. 31 Voltage at the grid in two area wind-PV-FC integrated system with Dynamic system optimization control

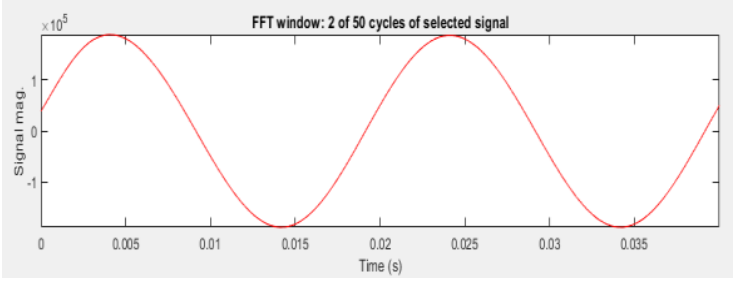

Fig. 32 FFT Analysis of voltage at the grid

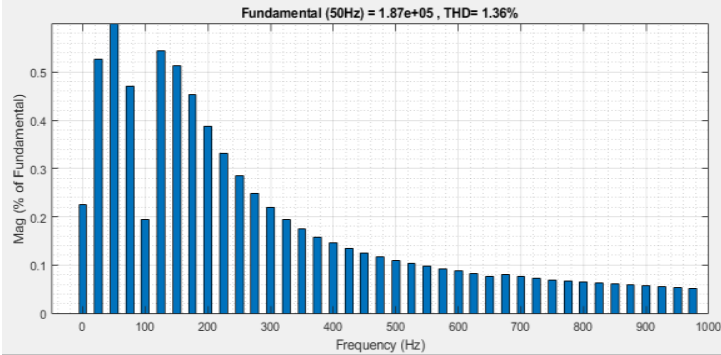

Fig. 33 THD $\%$ in voltage at the grid

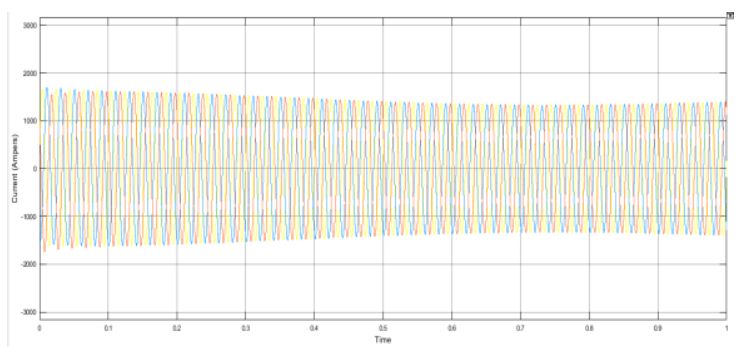

Fig. 34 Current at the grid in two area wind-PV-FC integrated system with Dynamic system optimization control

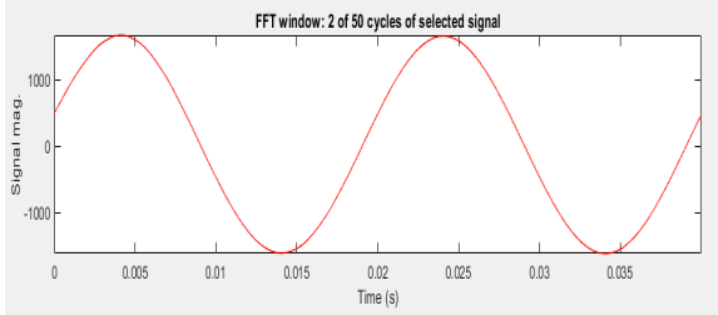

Fig. 35 FFT Analysis of current at the grid

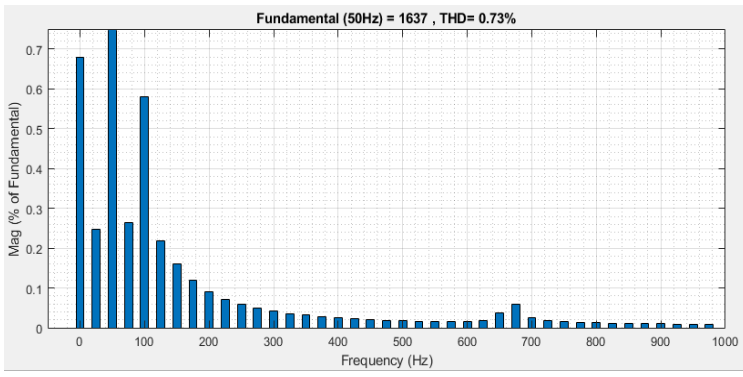

Fig. 36 THD\% in current at the grid

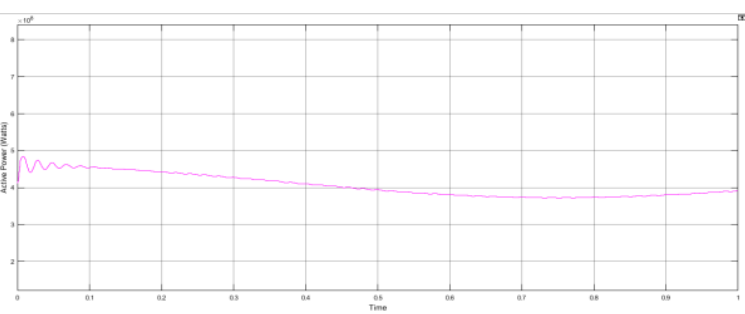

Fig. 37 Active power at the grid in two area wind-PV-FC integrated system with Dynamic system optimization control

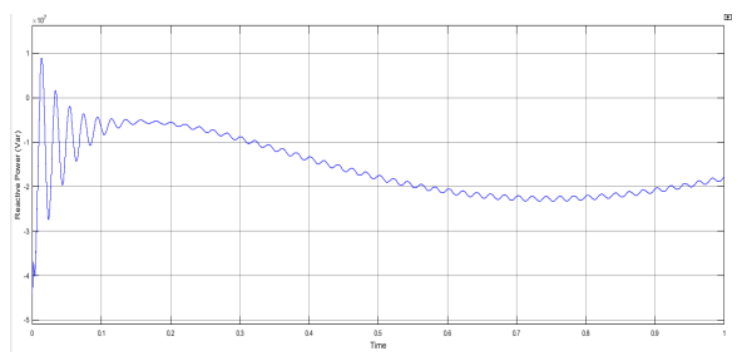

Fig. 38 Reactive Power at the grid in two area wind-PV-FC integrated system with Dynamic system optimization control

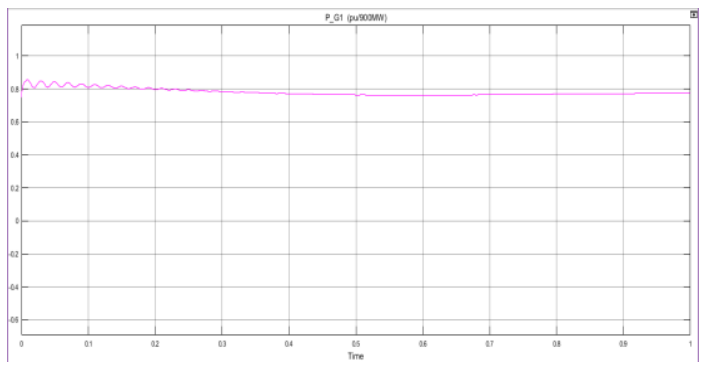

Fig. 39 Power stability in p.u at the generating terminal of machines with Dynamic system optimization control

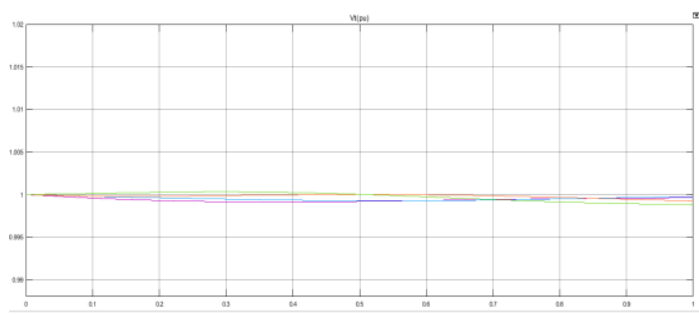

Fig. 40 Rotor Speed variations on wind/Solar/FC integration with Dynamic system optimization control 


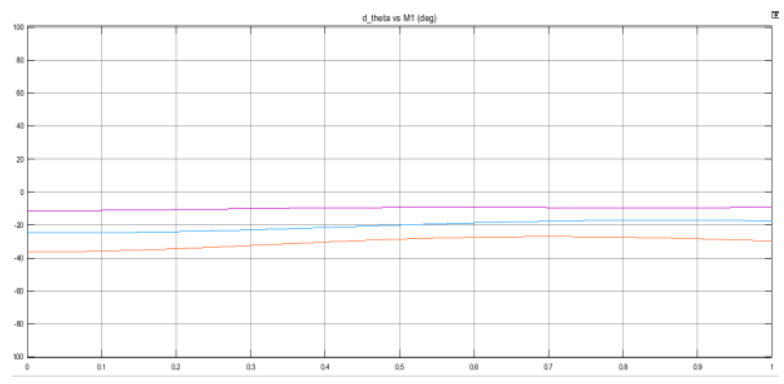

Fig. 41 Rotor angle deviation in machines with wind/solar/FC integration and controller

\subsection{Validation}

The effectiveness of the grid dynamics optimization control in the two area system has been studied in various aspects. The concluding remarks has been given after carrying out the comparative analysis of the three test systems with respect to power stability at the generating terminal, electrical power of individual machines, rotor angle stability and total harmonic distortion of voltage and current waveforms.

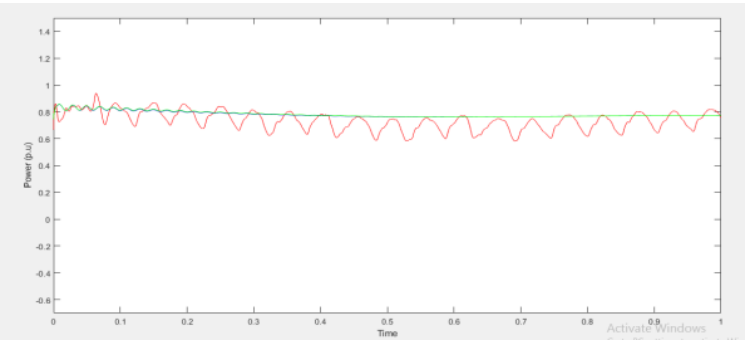

Fig. 42 Comparative graphs of power stability in p.u at the generation terminal

This graph shows the power stability at the generating bus of the power system in p.u. The red graph is of the system in which there is no Dynamic system optimization control which results in instable power at the bus after its integration with the renewable energy resources. The effect is due to the variable power feeding quality of green resources when subjected to variable environmental conditions.

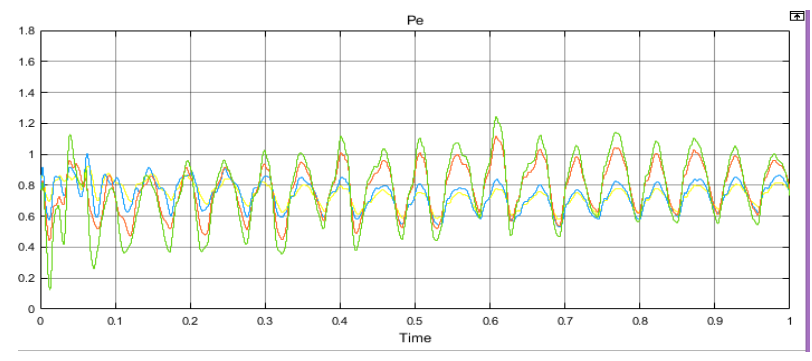

Fig. 43 Electrical power Pe (p.u) in machines in case 1

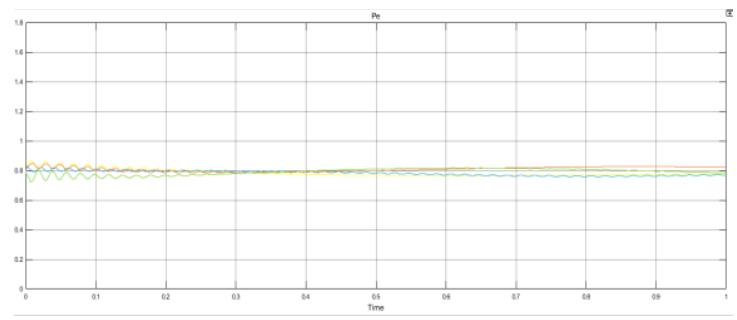

Fig. 44 Electrical power stability $[\mathrm{Pe}(\mathrm{p} . \mathrm{u})]$ in machines in case 2

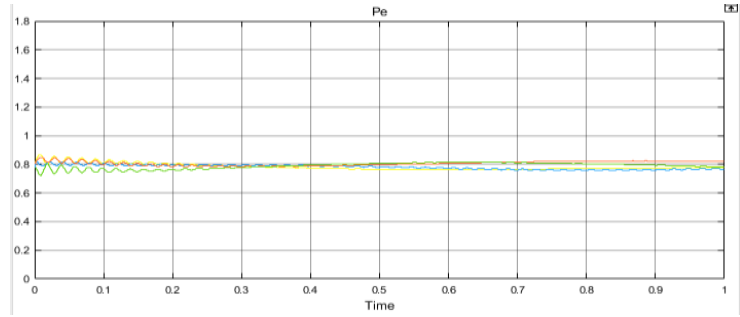

Fig. 45 Electrical power stability [Pe (p.u)] in machines in case 3

The graphs depict the electrical power Pe of the machines in the two area system on integration with wind energy resources and further with solar and Fuel cell as well. The graph in case 2 and three shows more stable power of the machines in which the proposed Dynamic System Optimization control has been incorporated.

Table 5: Comparison of using Dynamic System Optimization control while integrating renewable resources in two area system

\begin{tabular}{|l|l|l|}
\hline Systems & THD\% in voltage & THD\% in current \\
\hline Case 1: & $9.71 \%$ & $11.38 \%$ \\
\hline Case 2: & $1.34 \%$ & $0.70 \%$ \\
\hline Case 3: & $1.36 \%$ & $0.73 \%$ \\
\hline
\end{tabular}

The table further sums up the distortion levels created in the voltage and current waveforms of the grid at the time of the integration with the renewable energy resources. The grid voltage and current in case 1 without Dynamic system optimization control was $9.71 \%$ and $11.38 \%$ at the moment of the wind energy integration system. It was brought down to the $1.34 \%$ and $0.70 \%$ in case 2 where the two area system has been integrated with two variable energy resources at area 2 due the effective controlling of Dynamic system optimization control. In case three the system is integrated with another clean resource fuel cell generation at area 1 . In this the distortion rises slightly as compared to case 2 to $1.36 \%$ in voltage and $0.73 \%$ in current at the grid. However the modification in the kundur's two area system in case 3 having three other renewable energy generating resources the $\mathrm{THD} \%$ still is below than that in case 1 where there is no Dynamic system optimization control. 
The optimized controlled technique deployed in the power system has lead to an enhance power system performance and better stability of the four machines blinked with the grid in Kundur two area system.

\section{CONCLUSION}

There are several technical issues associated with grid connected systems like Power Quality Issues, Power and voltage fluctuations, Storage, Protection issues, Islanding. Power Quality issues are harmonics and voltage and frequency fluctuations. To study the system performance under the effect renewable energy based generating units the kundur's two area system has been taken as test system. The direct integration of these resources were studied for various instability issues like rotor angle stability, power stability at the generating points of machines and distortion level in the voltage and current waveforms of the grid system. The work has proposed a universal dynamic system optimizing control for system stability enhancement in all the aspects. The MATLAB/SIMULINK environment being the platform for the system designing and implementation, The effects on the two area four machines system has been studied by integrating wind energy system without dynamics optimization control in area land then systems with both solar and wind with the dynamic optimization controller at area 2 was developed. The study is further carried to integration of fuel cell system in area 1 as well.

To achieve the best performance form the dynamics controller the system parameters are optimized by subjecting it to neural network based forward learning mechanism. The following key conclusions were drawn from the system

- The THD $\%$ in voltage $1.36 \%$ and $\mathrm{THD} \%$ in current was $0.76 \%$ in final system having wind/solar/FC with proposed dynamic system optimizing control for system stability enhancement which is considerably reduced than in the system without controller with THD $\%$ in voltage to be $9.71 \%$ and THD\% in current to be $11.38 \%$ at the time of integration

- The electrical power Pe of the machines in the system without controller was highly unstable and dynamic than in case of the system with dynamic system optimizing control with $\mathrm{NN}$ learning.

- The rotor angle stability and power stability at the point of generation bus was also stabilized by the proposed control in the power system.
Thus the proposed NN learning based control of the dynamic system optimizing control for system stability enhancement can be a better option for integrating any type of renewable energy resource based generating system with the grid as it can mitigate most of the quality issues arising due to it.

\section{VII.FUTURE WORK}

In this project we have designed An universal grid optimization controller to consider maximum problems associated with the stability in machines for two area system each area consisting of two generators. The same can be extended to more area system or for a larger system. The work done in this project forms the base for larger power system networks.

\section{REFERENCES}

[1] Mohammad javad Morshed, Afef Fekih "A coordinated control for voltage and transient stability of multi-machine power grids relying on wind energy" International Journal of Electrical Power \& Energy Systems 109(July 2019):95-109 · July 2019.

[2] E. Sharifi \& A. H. Mazinan "On transient stability of multimachine power systems through Takagi-Sugeno fuzzy-based sliding mode control approach" Complex \& Intelligent Systems volume 4, pages171-179(2018)

[3] Mahmoud Reza Shakarami, I. Faraji Davoudkhani "Wide-area power system stabilizer design based on Grey Wolf Optimization algorithm considering the time delay" IETE Journal of Research Published 2016.

[4] Ram Krishan, Ashu Verma, Sukumar Mishra "Design of MultiMachine Power System Stabilizers with Forecast Uncertainties in Load/Generation" IETE Journal of Research Published 2019

[5] Butti Dasu, Mangipudi Sivakumar, "Interconnected multi-machine power system stabilizer design using whale optimization algorithm" Published 2019.

[6] Afef Fekih, Mohammad Javad Morshed, "A Nonlinear Control Design to Improve the Dynamic Stability of a Multi-Machine Power System with DFIG-Based Wind Turbines" 2018 Annual American Control Conference (ACC)

[7] A. Khodabakhshian, Mohammad Javad Morshed, M. Parastegari "Coordinated design of STATCOM and excitation system controllers for multi-machine power systems using zero dynamics method" International Journal of Electrical Power \& Energy Systems, Published 2013.

[8] Godpromesse Kenné, Jean de Dieu Nguimfack-Ndongmo “An Online Simplified Nonlinear Controller for Transient Stabilization Enhancement of DFIG in Multi-Machine Power Systems" IEEE Transactions on Automatic Control, Published 2015.

[9] B. Chaudhuri, N. R. Chaudhuri "Considerations toward coordinated control of DFIG-based wind farms" Published 2014.

[10] M. Javad Morshed, Afef Fekih "A new fault ride-through control for DFIG-based wind energy systems" Published 2017.

[11] Embaiya Salih, Stefan Lachowicz, Octavian Bass and Daryoush Habibi, "Application of a superconducting magnetic energy storage unit for power systems stability improvement", 1st International Conference on Green Energy (ICGE), pp. 267-272, 2014.

[12] Gundala Srinivasa Rao and Dr. A.Srujana, "Transient Stability Improvement of Multi-machine Power System Using Fuzzy 
Controlled TCSC", International Journal of Advancements in

Research \& Technology, Vol. 1,pp.1-11, Issue 2, July 2012. 